\title{
«El curioso impertinente»: Nuevas perspectivas críticas
}

\author{
GEORGES GÜNTERT*
}

Quien comienza a trabajar sobre el Quijote en su conjunto o sobre algún episodio particular de esta universal obra advierte pronto cómo la bibliografía cervantina ha ido creciendo, a lo largo de las últimas décadas, hasta convertirse en un corpus inmenso, casi inabarcable. Cada generación de investigadores contribuye a la reflexión crítica con nuevos estudios que multiplican los puntos de vista y enriquecen el conocimiento de los textos, a la vez que cuestionan los consensos de las generaciones precedentes. Ante este amplio panorama de sugerencias y propuestas no es fácil seleccionar las aportaciones más relevantes y reconocer, en la incesante controversia de opiniones, algo así como una convergencia de ideas. Si no obstante intento pasar revista a los estudios más recientes acerca del «Curioso impertinente», no es con la pretensión de ofrecer una lista exhaustiva de interpretaciones: prefiero ceñirme a un número limitado de trabajos, examinar de cerca sus procedimientos metodológicos y comparar sus conclusiones con las de mi propia lectura. Mi reflexión crítica se desarrollará en tres etapas: en primer lugar, examinaré algunas propuestas relacionadas con las fuentes de esta novela; no concluiré esta sección sin haber dado particular relieve bien a la lectura comparada de dos estudiosas italianas sobre los «pecados de curiosidad» en Ariosto y Cervantes, bien al ensayo de un cervantista inglés, quien sostiene la originalidad del «Curioso» y propone una lectura a su vez original de esta novela; después, presentaré dos interpretaciones morales de la misma, obra de sendos hispanistas alemanes, quienes, amén de analizar la trama del «Curioso», se preguntan sobre el tipo de interdependencia que existe entre su asunto y el de la historia principal; por

* Universidad de Zúrich. 
último, insistiré en la necesidad de superar una lectura limitada a las cuestiones argumentales y de prestar la debida atención a los aspectos narrativos y discursivos, que contribuyen, a su vez, a potenciar el sentido del texto.

\section{¿FUENTES O SUGERENCIAS?}

La mayoría de los cervantistas de hoy admite la existencia de analogías temáticas entre «El curioso impertinente» y un fragmento de las Historiae de Heródoto, en el que se narra la leyenda de Candaules, rey de Lidia, y de su valido Giges (Herodotus: 1987, I, 7-14). La propuesta de considerar esta leyenda como fuente, ya formulada por Jeremiah Ford en 1928, reaparece a partir de los años sesenta en los estudios de Francisco Ayala, Helmut Hatzfeld y Paul M. Arriola (Arriola 1971: 33-34). ¿Qué es lo que cuenta el historiador griego? El rey Candaules, orgulloso de estar casado con la mujer más hermosa del mundo, se prodigaba en elogios hacia ella. Viendo que Giges no estaba muy convencido, le invitó a verla desnuda con la justificación, devenida proverbial, de que «los hombres desconfían más de sus oídos que de sus ojos». Giges, aunque desaprobaba la idea, obedeció y se dispuso una noche a espiar a la reina desde un escondite. Pero la reina se dio cuenta de su presencia: al día siguiente, le mandó llamar y le dio a escoger entre morir al instante o casarse con ella, después de asesinar a Candaules. La historia acaba con el asesinato del monarca a manos de Giges y, por tanto, con un cambio de dinastía, que es lo que a Heródoto le importaba mostrar. El famoso «anillo de Gyges» -mencionado en la República de Platón-, que vuelve invisibles a sus portadores, todavía no aparece en su versión ${ }^{1}$.

Conviene esclarecer, de entrada, que la leyenda de Candaules no es la fuente principal del «Curioso», por el simple hecho de omitir su principal sintagma narrativo: la vanidad de Candaules no es la curiositas de Anselmo. Anselmo, incapaz de confiar en su esposa, quiere alcanzar una certeza absoluta respecto de su fidelidad, por lo que decide someterla a prueba, obligando a su mejor amigo a ayudarle en esta empresa. Existen, no obstante, algunas semejanzas, sobre todo en el comienzo: los puntos de encuentro están en la imprudencia del marido y en las serias objeciones morales de su confidente, que considera «insano» su propósito. En cuanto al fenómeno del voyeurismo, es cierto que se da en ambos relatos, pero en circunstancias distintas y con objetivos diversos.

Podemos afirmar a ciencia cierta que Cervantes conocía la leyenda de Candaules, no solo porque el ejemplo de este rey imprudente formaba parte del patrimonio cultural de su época, sino también porque existen claras pruebas de su presencia en el Quijote (Cervantes 2005: I, 291). La leyenda resultaba familiar a Lope de Vega, quien la recuerda en el libro quinto de su narra- 
ción El peregrino en su patria (1604), donde alude, a propósito de mujeres crueles, «a la mujer de Candaules, que por venganza de haberla enseñado a Giges desnuda, le entregó el reino, como refiere Heródoto» (Lope de Vega 1973: 468). Covarrubias completa su retrato de Candaules con la siguiente moraleja: «Ejemplo para los que hacen demasiada confianza en los amigos en cosa de tanto peligro y que no se debe fiar a nadie» (Covarrubias 2006: 426). En la antigüedad, recuerdan esta historia autores tan señalados como Cicerón, Plutarco y Justino, así como algunos padres de la Iglesia. En el umbral de la era moderna, vuelve a narrarla Boccaccio en su obra De casibus virorum illustrium, que tuvo fortuna europea (Boccaccio 1983: 176-177). ${ }^{2}$ Los miniaturistas franceses representan, desde 1400, los motivos del voyeurismo y el asesinato del rey Candaules, y sus más antiguas ilustraciones se encuentran precisamente en traducciones de las obras de Boccaccio ${ }^{3}$. Cabe señalar que fue el Canciller Pero López de Ayala quien, poco antes de morir, virtió en lengua castellana la primera traducción francesa de Laurent de Premierfait. ${ }^{4}$ En la España del siglo XV, en las satíricas Coplas de Mingo Revulgo glosadas por Hernando del Pulgar, aparece la figura del vicioso pastor Candaules, trasunto del rey Enrique IV de Castilla (Pulgar 1929: 169). También conocen la leyenda los escritores del Renacimiento Hans Sachs, Cristóbal de Villalón, Rabelais, Montaigne y William Painter, así como algunos pintores y coleccionistas de emblemas: piénsese en el "Gige e Candaulo» de la Galleria Borghese, obra juvenil de Dosso Dossi (1510), o en las representaciones del rey y marido imprudente incluidas en los Emblemata de Johannes Sambucus (Amberes, 1564) y de Nicolaus Reusner (Francfort, 1581) ${ }^{5}$. Desde el siglo XV, además, las Historias de Heródoto estaban disponibles en latín, gracias a la labor filológica de los humanistas Guarino Veronese y Lorenzo Valla, y a partir de 1533 circulaba también la versión italiana del conde Matteo Boiardo, que tuvo varias reimpresiones (Pichler 1986: 82-94) .

2. La fuente de Boccaccio es Justino, el autor de los Historiarum Philippicarum libri XLIV (I, 7, 14-19). Véanse, a este propósito, las notas en (Boccaccio 1983: 937).

3. La Biblioteca de Ginebra posee un ejemplar de la segunda versión francesa de De casibus virorum illustrium (1409) que incluye una preciosa miniatura relacionada con la leyenda de Heródoto (Ms. fr. 190, vol. 1, f. 74): la imagen muestra a la reina de Lidia tumbada en la cama y observada por los dos varones Giges y Candaules. Hacia 1440, Maître Rohan pinta una escena de tema análogo (BNF París, Ms. fr. 228, fol. 56). En la segunda mitad del siglo XV, Maître François, ilustrando el cap. I, 20 de una traducción del De civitate Dei de San Agustín, representa, a su vez, la escena del asesinato (BM Nantes, fr. 8, fol. 25r).

4. La primera versión francesa del De casibus es de 1400, y López de Ayala murió en 1407 (Alvar 2001: 343).

5. El ejemplo de Candaules y Giges figura en la colección del médico húngaro Johannes Sambucus, Emblemata cum aliquot nummis antiqui operis, Amberes, Platini, 1564, y en la de Nicolaus Reusner, Emblemata, partim ethica et physica, Francoforti, Feyerabendt, 1581, donde lleva el mote Coniugij arcana non revelanda. Cfr. con (Henkel/ Schöne 1996: 1603).

6. Según indica Pichler, la primera versión completa de las Historias de Heródoto en latín es la de Lorenzo Valla (Venecia, 1474). Siguen la traducción italiana del conde Boyardo (Venecia 1533), la alemana de Hieronymus Boner (Augsburgo 1535), la francesa de P. Saliat (París 1556) y la inglesa de «B. R.» (Londres 1584) (Pichler: 1986: 82, n. 2). 
La prueba decisiva de que Cervantes conocía el ejemplo de Candaules se encuentra en la historia de Cardenio, narrada en el capítulo XXIV de la primera parte del Quijote. Su protagonista cuenta cómo se hizo amigo íntimo de Fernando, hijo segundo de un grande de España, hasta el punto de confesarle sus amores por Luscinda y de mostrársela una noche, en secreto. Así refiere Cardenio esta escena:

Alabéle la hermosura, donaire y discreción de Luscinda, de tal manera que mis alabanzas movieron en él los deseos de querer ver doncella de tantas partes adornada. Cumplíselos yo, por mi corta suerte, enseñándosela una noche, a la luz de una vela, por una ventana por donde los dos solíamos hablarnos. Vióla en sayo, tal, que todas las bellezas hasta entonces por él vistas las puso en olvido (Cervantes 2005: I, 291-292).

Es indudable que el recuerdo de la leyenda de Candaules ha inspirado esta escena, compuesta de dos amigos observadores, uno poderoso, el otro algo más humilde, y de la novia de este último, contemplada «a la luz de una vela». Cervantes ha imaginado un magnífico «nocturno», como los de la pintura contemporánea, desde Caravaggio hasta Georges de la Tour, por no hablar del flamenco Jacob Jordaens, a quien se debe no solo una «Adoración del niño» iluminada con una vela, sino también un famoso desnudo que representa a la esposa de Candaules ${ }^{7}$.

Otra temática que ha dejado huellas en el «Curioso» se relaciona con el mito de la perfecta amistad, tal y como lo proponen algunos relatos orientales y sus imitaciones en la España medieval, entre ellas, el «Cuento de los dos amigos» (Avalle-Arce 1975: 187-189; Barbagallo 1994: 207-211). De este cuento se conocen numerosas versiones en la literatura europea: desde la Disciplina clericalis de Pedro Alfonso y el Decamerón de Boccaccio hasta La Galatea de Cervantes, quien refiere, en varios capítulos de su libro pastoril, las intrincadas peripecias de Timbrio y Silerio, enamorados de la misma dama (Avalle-Arce 1975: 182-189). Ahora bien, el mero hecho de aparecer, en los primeros párrafos de «El curioso impertinente», la expresión «los dos amigos» bastó a algunos críticos para considerar la novela interpolada una nueva ejemplificación del célebre motivo. La historia de Anselmo, Lotario y Camila, sin embargo, no puede entenderse como una variante del mito de la amistad heroica. El «Cuento de los dos amigos» consiste en la narración de dos supremas pruebas, que solo el verdadero amigo consigue superar: tiene que estar dispuesto a renunciar, en aras de la amistad, a la mujer amada y a su propia vida. Juan Bautista Avalle-Arce, tras sostener que «El curioso impertinente» constituye la etapa última en el desenvolvimiento de la historia de los amigos, llega a la conclusión de que «es al mismo tiempo su destrucción» (Avalle-Arce 1975: 189). El «Curioso», con todo, no contiene ninguna de las dos pruebas que constituyen el núcleo temático del antiguo motivo. Yo no

7. Este cuadro de Jordaens, pintado hacia 1646, se halla hoy en el Museo Nacional de Estocolmo. 
hablaría, por tanto, de «fuente», sino de un mito que Cervantes evoca en el comienzo para, a continuación, alejarse de él en su trama novelesca.

Conviene tener en cuenta aún otra filiación, investigada en el recién publicado libro de Francisco Javier Bravo Ramón, El curioso impertinente: periplo mediterráneo de un mito clásico. El mito en cuestión considerado aquí como fuente principal del «Curioso», a mi modo de ver con excesiva confianza, es el de Céfalo y Procris, que pertenece no solo a la literatura griega, sino también a Ovidio, Boccaccio y Ariosto. Este último le dedica dos cuentos en su Orlando furioso, y el protagonista de uno de ellos es el «doctor Anselmo», aunque, contrariamente a lo que Lotario supone, no es este doctor quien bebe de la copa. La influencia del mito ovidiano culmina en el teatro del Renacimiento, con la Fabula di Cefalo de Niccolò da Correggio, representada desde 1487 en Ferrara, en presencia del joven Ariosto (Bravo Ramón 2013: 156). Cabe recordar que, en el Persiles de Cervantes, los peregrinos, después de pisar suelo español cerca de Badajoz, se cruzan con una compañía de farsantes que representa un drama sobre el mismo asunto (Cervantes: 20034: 446). Será por eso por lo que Bravo Ramón insiste en el carácter dramático de este mito, llegando a sugerir que Cervantes «podría haberlo visto representado» (Bravo Ramón 2013: 201). En efecto, el mito de Céfalo, gracias a sus recursos teatrales, gozará de gran popularidad no solo en la comedia española, sino también en el teatro musical del siglo XVII, como lo atestigua la ópera de Juan Hidalgo Celos aun del aire matan, basada en un libreto de Calderón (Stein 2014: IX-XIII).

Si tratamos de resumir el mito en su versión ovidiana, vemos enseguida que su protagonista, Céfalo -con la complicidad de la diosa Aurora, que despierta en él los celos- pone a prueba la fidelidad de su mujer: se disfraza de mercader y tienta con regalos a su esposa, que no le reconoce; insiste en su obra de seducción hasta que advierte cierta vacilación en ella. Esto le basta para que se quite la máscara y acuse a Procris de infidelidad. No obstante la inevitable crisis matrimonial, los esposos se reconcilian. Pero, en la segunda parte del mito, a consecuencia de una serie de malentendidos, es Procris quien cree que Céfalo la traiciona: este, habiendo salido a cazar, la confunde con un animal y la mata con su jabalina, que era un regalo de Procris (Ovidius 1968: 266-275) ${ }^{8}$. El mito era conocido en la Edad Media y servía de amonestación contra la enfermedad de los celos. Así, en el Ovide moralisé se lee que «premièrement se doit garder sur toutes choses le saige mary d'estre jaloux de sa femne et ne doit d'elle enquérir la chose qu'il ne vouldroit trouver». ${ }^{9}$ Análogamente, un comentarista de las Metamorfosis del siglo XVI, Jorge de Bustamante, autor de Las transformaciones de Ovidio en lengua española (Amberes, 1595), escribe: «La historia de Céphalo y Procris

9. Ovide moralisé, ed. de Vicente Cristóbal, en (Bravo Ramón 2013: 138-139). 
significa (como nos advierten las sacras letras) que el hombre no debe procurar saber más de lo que le conviene saber, porque incurrirá siempre en el error de Céphalo, que pasó de una vida feliz a una mísera y llena de infelicidad» (Bravo Ramón 2013: 143).

La cuestión de si en la vida matrimonial conviene o no llevar a cabo experiencias semejantes es tratada por Ariosto en el canto XLII del Orlando furioso, en el episodio de la copa de oro, de la que rehúsa beber Rinaldo, un personaje recordado de modo explícito en «El curioso impertinente». Es Lotario, en su largo discurso exhortativo, quien trae a la memoria de Anselmo «la prueba del vaso [...] que se escusó de hacerla el prudente Reinaldos» (Cervantes 2005: I, 420). El dueño del castillo que le tiende la copa, a su vez víctima del experimento, se expresa de modo ambiguo: «Se vuoi saper se la tua [moglie] sia pudica / (come io credo che credi, e creder déi); / [...] tu per te stesso, senza ch'altri il dica, / te n'avvedrai, s'in questo vaso béi» (Ariosto 1966: 1261). Rinaldo, tentado por la idea de alcanzar una certeza definitiva, acerca la copa a sus labios, pero, antes de beber, se detiene un momento a reflexionar y renuncia a la prueba, proclamando: «Ben sarebbe folle / chi, quel che non vorria trovar, cercasse. / Mia donna è donna, et ogni donna è molle: / lascián star mia credenza come stasse. / Sin qui m'ha il creder mio giovato, e giova: / che poss'io megliorar per farne prova?» y concluye: «Or questo vin dinanzi mi sia tolto: / sete non n'ho, né vo' che me ne vegna; / che tal certezza ha Dio più proibita, / ch'al primo padre l'arbor de la vita» (Ariosto 1966: 1263-1264). Estos últimos versos, con su significativa alusión al estado edénico de los primeros hombres, muestran a las claras que Ariosto, al igual que Cervantes, insiste en el dilema creer vs. conocer, y precisamente a este dilema se refiere Lotario, en el comienzo de su discurso, cuando actúa aún como buen consejero y leal amigo:

Dime, Anselmo, si el cielo, o la suerte buena te hubiera hecho señor y legítimo posesor de un finísimo diamante, de cuya bondad y quilates estuviesen satisfechos cuantos lapidarios le viesen, y que todos a una voz y de común parecer dijesen que llegaba en quilates, bondad y fineza a cuanto se podía estender la naturaleza de la piedra, y tú mesmo lo creyeses así, sin saber otra cosa en contrario, ¿sería justo que te viniese en deseo de tomar aquel diamante y ponerle entre una yunque y un martillo, y, allí, a pura fuerza de golpes y brazos, probar si es tan duro y tan fino como dicen? (Cervantes 2005: I, 421).

Una última observación acerca de este mito. A quienes consideran «Céfalo y Procris» como fuente exclusiva del «Curioso» -además de Bravo Ramón, lo hace su maestro, el helenista José María Lucas de Dios ${ }^{10}-$, se les debe recordar que, si bien esta vez aparece la prueba, consistente en una tentativa 
de seducción, falta por completo la complicidad del amigo -Céfalo actúa a solas-, por lo que es evidente que Cervantes no se limitó a reinterpretar el mito ovidiano con vistas a las variantes que le ofrecía el Orlando furioso. Según Diana de Armas Wilson, son cuatro los modelos principales que influyeron en la génesis de «El curioso impertinente»: la leyenda de Candaules, la prueba del vaso narrada en el Orlando furioso, el cuento de «Los dos amigos» y «Cupido y Psique», la novela intercalada en El asno de oro de Apuleyo (Wilson de Armas 1987: 14-18). Se le podría objetar que el grado de influencia de estas «fuentes» es desigual y que los motivos de la curiositas de Psique, esto es, su miedo e inseguridad, difieren mucho de la ambición de Anselmo. Ello no obstante, es cierto que Cervantes combinó elementos procedentes de distintos relatos para inventar una trama propiamente suya y para poder cargarla de un significado que fuese más allá del drama matrimonial de Anselmo, Lotario y Camila.

\section{UNA LECTURA COMPARADA: ORLANDO FURIOSO XLII-XLIII - QUIJOTE, I, 33-35}

Las dos autoras de este estudio, la italianista María Cristina Cabani y la hispanista Giulia Poggi, se mueven con notable destreza tanto en el laberinto narrativo del Orlando furioso como en la selva del Quijote, por lo que parecen predestinadas a ofrecer una lectura competente de ambas obras (Cabani/Poggi 2006: 5-31). A los lectores poco familiarizados con el poema de Ariosto les informan debidamente sobre los tres relatos que tienen que ver con el tema de la curiosidad insana: el del paladín Rinaldo, quien, después de beber en la fuente del desamor, ha recobrado finalmente su equilibrio moral, lo que le permite afrontar con serenidad la prueba del vaso de oro (XLII, 28-104; XLIII, 6-8); el de su anfitrión, quien le cuenta llorando su propia desgraciada historia: la maga Melissa le ayudó a adoptar la imagen de un admirador de su mujer y a seducirla con joyas, lo que dio lugar a que esta le abandonase y se fuese a vivir con su rival (XLIII, 9-46); y el del juez Anselmo, que un barquero del Po narra a Rinaldo durante su viaje hacia Ferrara: esta vez, el seductor no es el marido, sino un antiguo pretendiente de la esposa. El doctor Anselmo se ha limitado a consultar a un astrólogo, que le ha pronosticado su desdicha conyugal. Lo que importa señalar en este relato es que tanto la infidelidad de la mujer como el desliz del marido, una experiencia homosexual, se cometen por interés; no obstante, todo acaba con la reconciliación de la pareja (XLIII, 69-143). Los dos cuentos, que se distinguen por el tono -trágico el del caballero, cómico-grotesco el del barquero-, tienen como receptor a Rinaldo, quien se ve confirmado, a la postre, en su sabia decisión de no haber cedido a la curiosidad. Ahora bien, lo que se debería evidenciar en una valoración de los cantos XLII-XLIII es el hecho de que los relatos del anfitrión y del juez Anselmo no son sino variantes del mito de Céfalo y Procris: en ambos 
intervienen diosas o magas (Aurora en Ovidio, Melissa y Manto en Ariosto), que despiertan los celos en el ánimo del marido, facilitan su transformación y le proporcionan los objetos mágicos (joyas, un perrito que produce oro); lo cual concuerda con la invectiva contra la «execranda avaricia» con la que el narrador introduce este canto (XLIII, 1-5). No ocurre así en el caso de Rinaldo, donde no es cuestión de interés, sino de un serio conflicto moral entre el deseo de saber y el respeto de la confianza conyugal. De ello se infiere que solo el dilema de Rinaldo anticipa el debate moral entre Anselmo y Lotario, como lo presenta la novela cervantina, y que solo sus consideraciones acerca de la inutilidad del experimento son fuente del «Curioso».

En su análisis comparado, Cabani y Poggi postulan la existencia de «estrategias narrativas comunes» en Ariosto y Cervantes. Su hipótesis no deja de ser problemática, pues la afinidad entre ambas obras se basa algunas veces en semejanzas meramente léxicas y en paralelismos más bien aparentes. Así, las dos estudiosas, con respecto bien a los últimos versos del canto XLII del Orlando furioso (Rinaldo levanta la copa, pero, antes de beber, reflexiona), bien a la interrupción de la novela cervantina en el capítulo XXXV del Quijote, reconocen una misma «técnica del aplazamiento», con el propósito de estimular la expectación en el ánimo del lector. Es cierto que todo narrador recurre a elementos de suspense y que una dilación puede contribuir a aumentar la curiosidad; pero, en los casos mencionados, las estrategias narrativas difieren. Ariosto concibe la lectura de su poema como un proceso alternado de ilusión y desilusión; por eso, sus cantos se abren con un parlamento del narrador que induce a los lectores a meditar, liberándoles temporalmente del encanto en que las aventuras narradas les han dejado. Si su narrador, entre un canto y otro, concede a Rinaldo una pausa reflexiva, es con la intención de configurar la sabia actitud que Ariosto recomienda a sus lectores. Dicho de otro modo: la prudencia del paladín remite a la necesidad de moderar con la razón los excesos pasionales. La interrupción del «Curioso» en el capítulo XXXV, en cambio, requiere una explicación distinta, como veremos en la página 137 de este estudio. Me limito, por ahora, a señalar un único punto: si la intención principal de Cervantes hubiese sido la de despertar la curiosidad del lector, no habría anticipado el desenlace trágico de la novela, concluyendo el capítulo XXXIV con la prolepsis: «Duró este engaño algunos días, hasta que al cabo de pocos meses volvió Fortuna su rueda, y salió a plaza la maldad con tanto artificio hasta allí cubierta, y a Anselmo le costó la vida su impertinente curiosidad» (Cervantes 2005: I, 451). Considero igualmente cuestionable el modo en que las dos autoras asocian la actitud del cura y de sus oyentes, curiosos por conocer el contenido del manuscrito, con la curiositas de Anselmo, ya que escriben: «Dedicata a un peccato di curiosità, [la novella] viene letta per curiosità in modo da stimolare la curiosità» (Cabani/Poggi 2006: 16). Aunque esta formulación puede tomarse como un juego verbal, cabe recordar que en la época de Cervantes se tenía muy clara la distinción entre las dos acepciones del concepto: a saber, entre la studiositas o el deseo de aprender, que es natural y lícita a los hombres, y la vana et curiosa cupiditas de quienes pretenden 
entremeterse en la vida íntima del prójimo o adivinar el futuro, apropiándose un derecho que no les corresponde ${ }^{11}$.

Cabani y Poggi concluyen su lectura con una interpretación psicoanalítica del comportamiento de Anselmo, a quien juzgan no solo «loco», sino «enfermo». Es cierto que la palabra «enfermedad» aparece en un comentario del propio Anselmo, cuando compara su irrefrenable deseo con los antojos de las embarazadas o con lo que Huarte de San Juan llama la malacia (Huarte de San Juan 1989: 480-482). Pero, como ha mostrado Steven Hutchinson, no se trata sino de una comparación, ya que Anselmo «no tiene la enfermedad que dice que tiene» (Hutchinson 2006: 130). Aun así, su curiosidad intelectual parece arraigar en una zona morbosa de su psique. Francisco Ayala habla del «extraño y morboso deseo del recién casado» (Ayala 1971: 709) y Ciriaco Morón Arroyo supone una «dependencia enfermiza» de uno de los amigos con respecto al otro (Morón Arroyo 2000: 167), pero ¿cómo conciliar ese psicologismo moderno con el mito que el texto inicialmente postula? Otros suponen en Anselmo tendencias homosexuales, sin considerar que su voyeurismo tiene objetivos más cognitivos que eróticos. «Anselmo experimenta emociones, no de participante, sino de espectador», observa al respecto Steven Hutchinson (Hutchinson 2006: 134). El problema consiste, a mi modo de ver, en que los personajes del «Curioso» no salen ni de una novela post-freudiana ni de una Florencia históricamente identificable, sino de un modelo narrativo abstracto que contrapone el estado ideal del comienzo a la más caótica realidad del final. El análisis de los caracteres no puede prescindir de las propiedades de este modelo. Pues bien, en opinión de las dos autoras, la conducta de Anselmo obedece a una tendencia autodestructiva. Cervantes, según ellas, hace «de la pulsión autolesiva del protagonista el motor de toda la acción novelesca» (Cabani/Poggi 2006: 29). Desde esta perspectiva, Anselmo «no se parece a ninguno de los personajes del Orlando furioso»: ni al prudente Rinaldo; ni a su anfitrión, movido por los celos; y ni mucho menos al juez Anselmo, quien, aun siendo culpable, es lo suficientemente hábil como para salvar su relación conyugal. Mientras que los personajes de Ariosto «se dejan llevar por su instinto de autoconservación» y aun «por el autoengaño», el protagonista del «Curioso» aparece como víctima de su «instinto autodestructor» (Cabani/Poggi 2006: 30). Una forma de masoquismo, por lo tanto. Pero, ¿puede decirse que Anselmo actúa tal y como actúa en aras de su propia destrucción? Quien, como él, quiere saber la verdad cueste lo que cueste, ¿no aspira más bien al dominio, al triunfo, al conocimiento teórico de la vida (a la que no consigue adherirse emotivamente)? El análisis psicoanalítico que han emprendido las dos autoras merece ser continuado ${ }^{12}$.

11. Consúltense, en particular, a San Agustín (Conf. X, 35) y a Santo Tomás de Aquino (Summa theol. $2^{\mathrm{a}}, 2^{\mathrm{ae}}$, quaest. 167 a.1), quien condena, entre los casos de la vana curiosidad, la tendencia a espiar la vida íntima del prójimo. Cfr. con la entrada «curiosité» en (Dictionnaire de la spiritualité 1958: fasc. XI, 2654-2662).

12. El estudio psicoanalítico de Cabani y Poggi tiene precedentes, a saber: (Gustavo Illades Aguiar 1995: 487-495) y (Eduardo González 1993: 200-226). 


\section{UNA NOVELA «SIN ANTECEDENTES CONOCIDOS»: LA COMPLE- JIDAD PSICOLÓGICA DE «EL CURIOSO IMPERTINENTE»}

El hispanista inglés Barry W. Ife, autor del ensayo «Cervantes, Herodotus and the Eternal Triangle» y de una edición bilingüe de las Novelas ejemplares, desconfía de quienes intentan explicar la trama del «Curioso» a partir de sus presuntas fuentes (Ife 2005: 671-681) ${ }^{13}$. Ife es reacio, asimismo, a considerar los cantos XLII y XLIII del Orlando furioso como antecedente de la novela cervantina, porque, según argumenta, «there is no sorceress in the Curioso, no other suitor, no disguise, no cup and no wine» (Ife 2005: 674). Es significativo que mencione, de entre los cuentos de Ariosto, solo el del anfitrión, que, en efecto, tiene escasa afinidad con la novela de Cervantes. Pero la semejanza entre ambas obras no consiste en la presencia del mágico vaso de oro, que proviene del mundo artúrico, ni del disfraz del seductor, que remite a la fábula de Céfalo y Procris, sino solamente en las reflexiones acerca de la utilidad de la prueba del paladín Rinaldo. El único texto antiguo al que Ife presta mayor atención es la leyenda del rey Candaules, que no le interesa en tanto que fuente, sino como parábola sobre la sexualidad y el poder, capaz de sugerir interrogaciones como la siguiente: ¿Por qué se le ocurrió a Candaules mostrar a su mujer desnuda a otro hombre? Análogas preguntas sobre el porqué de los actos deberían plantearse los lectores de la novela cervantina: ¿Por qué insiste Anselmo en que su amigo intente seducir a su mujer?, ¿por qué Lotario acaba por ceder?, y ¿por qué Camila se deja seducir? Estas preguntas, en opinión de Ife, ayudan a descubrir los motivos ocultos de los actos, que, en la psicología del subconsciente, se identifican con la libido y la ambición por el poder.

Las cuestiones psicológicas de «El curioso impertinente» que ha de solucionar el lector conciernen, por tanto, a las intenciones profundas que subyacen a los programas narrativos. Anselmo no necesita someter a prueba a su mujer, pero lo hace. Lotario rehúsa colaborar en esta empresa, pero cede cuando Anselmo le amenaza con proponérsela a otra persona. Empecemos con el caso del protagonista: según Ife, Anselmo desea conciliar dos cosas incompatibles, el matrimonio con Camila y la amistad con Lotario. Lo que intenta, por tanto, es incluir a Lotario en su vida matrimonial, invitándole «a ocupar su propio lugar». Ife distingue entre el plano de los propósitos declarados y los móviles del subconsciente, lo que le hace desconfiar de los significados explícitos: «The wife-testing is not the objective; it is the means to a quite different end»; lo que quiere decir, en términos llanos: «What Anselmo really wants to see through the keyhole is his friend making love to his wife» (Ife 2005: 678). Es posible. Pero, cabe preguntarse, ¿cuánto en sus ambiciones es pulsión y cuánto, intención consciente? El comportamiento de Anselmo, después del matrimonio, deja entrever un ánimo inquieto, ansioso por salvar su amistad con Lotario. Por otro lado, en la sociedad tradicional, la vida de casado no

13. Ife es coeditor de una traducción de las Novelas ejemplares: Barry y Thacker (2013). 
impedía que el marido disfrutase de la compañía de sus amigos. Un modus vivendi semejante al que los dos observaban en su vida de solteros, cuando Lotario prefería como pasatiempo la caza y Anselmo sus amoríos, podría darse también después del matrimonio. No obstante, la solución de verse con Lotario solo de vez en cuando no le basta a Anselmo: quiere incluir a ambos, amigo y mujer, en su triángulo afectivo, y a ambos los pierde.

Si Anselmo desea lo imposible, Lotario se revela un personaje aún más complejo. Su decisión de no interferir en la vida de los casados y su resistencia moral al proyecto del amigo no serían sino pretextos: en realidad, así opina Ife, también él desea a Camila y eso, desde el momento mismo en que, en nombre de Anselmo, fue a pedirla por esposa a sus padres. «No, this seduction is not sudden; it has been going on from the outset, and as the corrosion of suspicion spreads, we begin to realise that Lotario's avoidance of Anselmo after his marriage, and his resistance to Anselmo's pleas to carry out the test, have been cynical pieces of manipulation» (Ife 2005: 679). Desde esta perspectiva, Lotario aparece como un «cínico manipulador»: con su prolija insistencia no haría más que atribuir mayor valor a la autorización de Anselmo que, en el fondo, necesita y le conviene. Sin embargo, el texto no ofrece indicio alguno de una inicial simpatía recíproca entre Lotario y Camila. Cervantes no es Guillén de Castro, quien, en su drama homónimo, imagina un previo encuentro de los futuros amantes (Guillén de Castro 1991: 10-11 $)^{14}$. En la novela cervantina, son muchas las señales que nos muestran a un Lotario indignado: Lotario obedece a Anselmo a regañadientes y, solo después de haber transcurrido mucho tiempo con indiferencia hacia Camila, se enamora de ella. Si Lotario la hubiese deseado desde su primera visita formal, ¿por qué habría esperado tanto en manifestarle su inclinación? En lo tocante a Camila, sabemos que cede a los requiebros de Lotario solo después de verse abandonada por su marido; y decir que «cede», tal vez no sea correcto: la verdad es que «she is seduced, but not against her will» (Ife 2005: 679). Ife interpreta la situación que se ha creado hacia el final del capítulo XXXIV como un momento provisional de equilibrio: "Anselmo has his wife and his friend; Lotario has his friend's wife; and Camila has them both» (Ife 2005: 679). Se trata, con todo, de un equilibrio precario porque Anselmo queda excluido de la vida secreta de los amantes.

$\mathrm{Si}$ aceptamos las interpretaciones de esta lectura, se nos muestra una realidad psíquica bastante más compleja respecto a la que se manifiesta en los parlamentos de Lotario, respetuosos con el sistema de valores de la sociedad post-tridentina. Al descubrir la psique profunda de los caracteres, Ife desmiente nada menos que el moralismo de la novela, a la vez que pone en entredicho los argumentos éticos del narrador. La ejemplaridad, por consiguiente, no

14. El drama es imitación directa de la novela cervantina. Véase la introducción de Christiane Faliu-Lacourt y M. Luisa Lobato que ofrece un resumen detallado del drama (Guillén de Castro 1991: 12-21). 
puede ser la única clave de lectura de esta novela, que es objeto, a su vez, de una visión irónica y desengañada de la vida humana.

\section{DOS LECTURAS MORALES}

Dada la notoriedad de la edición comentada del Quijote, publicada con motivo del cuarto centenario bajo la dirección de Francisco Rico, me parece aconsejable comenzar con un examen de las páginas críticas que allí se dedican a la novela interpolada. El responsable del comentario de los capítulos XXXIII, XXXIV y XXXV de la primera parte es el hispanista alemán Hans-Jörg Neuschäfer, autor de alrededor de media docena de estudios sobre «El curioso impertinente» y los demás cuentos intercalados. No son todos originales: algunos son reproducciones editadas en ocasiones diferentes, otros analizan el «Curioso» en relación con las Novelas ejemplares o con la novelística europea. En los trabajos que he consultado, la postura del crítico frente al significado de la novela permanece sustancialmente idéntica. Su última contribución sobre el «Curioso» se encuentra en el volumen de actas Giovanni Boccaccio in Europa, donde examina las relaciones del Cervantes cuentista con la narrativa italiana, aunque sin insistir en la cuestión de las fuentes (Neuschäfer 2014: 103-112).

Conviene subrayar, a este propósito, que hasta ahora nadie ha sabido identificar un antecedente cierto del «Curioso» en la novelística italiana del siglo XVI y, mucho menos, en el Decamerón. ${ }^{15}$ Aunque algunos críticos continúan pensando que los precursores de los maridos celosos de Cervantes se encuentran en la novelística italiana $\mathrm{y}$, sobre todo, en la obra de Bandello, faltan hasta la fecha propuestas convincentes acerca de novelas que puedan considerarse efectivamente como fuentes directas del «Curioso» ${ }^{16}$. Para quien, como yo, esté acostumbrado a distinguir entre figuras y significados, semejanzas temáticas y analogías estructurales, no puede existir este modelo, dada la diferencia de género que cabe suponer entre la novelita burlesca y el entremés, por un lado, y la novela trágica, por otro. Los valores de la beffa son el erotismo y la vitalidad, contrariamente a lo que ocurre en el «Curioso», que incluye serias reflexiones éticas (y donde el único personaje que representa los

15. Véase el estudio de McGrady, quien propone como fuente una novela de Sermini (Mc Grady 1994: 767-772) y cfr. con mi comentario: (Güntert 2007: 130-131). Zimic descubre coincidencias temáticas en la novela XXI de la «Cuarta parte» de Bandello, donde es cuestión de un marido ingenuo que confía ciegamente en su amigo, en realidad su rival (Zimic 1998: 70, n. 16). Alarcos García, siguiendo a Hatzfeld, trata de relacionar el «Curioso» con el «Cuento de los dos amigos» y recuerda, al respecto, la versión que Boccaccio ofrece de este mito (Alarcos García 1950: 367). Otros aún, sin hablar de fuentes directas, señalan alguna semejanza con la novela de Bernabò y Zinevra (Decamerón, II, 9), que traslada la leyenda arturiana de la virtud calumniada de Ginebra al mundo mercantil (Krueger 2009: 125; Babinger 2013: 16).

16. Guillermo Carrascón sostiene que «el sedicente lombardo [Bandello] despertaba una particular simpatía, una especial sensación de intenciones, en el autor de las Novelas ejemplares», pero no señala ningún paralelo con «El curioso impertinente» (Carrascón 2014: 300). 
valores del discurso cómico es la criada Leonela). Consecuentemente, el triángulo de actores propio del género cómico-burlesco se compone del marido anciano, de su más joven rival y de su mujer deseosa de gozar, la cual suele tomar la iniciativa de la aventura amorosa. Así ocurre en la novela I-5 de Bandello, que se ha indicado como fuente de «El celoso extremeño» $\mathrm{y}$, en cierta medida, también del «Curioso», por más que su autor la introduzca con estas palabras: «Essa novella chiaramente dimostra che, quando una donna delibera ingannare il suo marito, che se egli avesse più occhi che Argo, che ella a la fine starà di sopra e gliela appiccherà» (Bandello 19664: I, 66) (Zimic 1994: 69-71; Di Pinto 1999: 273, n. 18). Con esto no se excluye la posibilidad de que Cervantes acogiese de sus amplias lecturas italianas algún que otro elemento figurativo ni se niega, claro está, su deuda con Ariosto. Pero es un hecho que, en ninguna de las novelas de celosos de Bandello, Giraldi Cinthio o Straparola, se nos muestra a un marido recién casado que, por ser incapaz de amar, someta a prueba la fidelidad de su esposa con la ayuda de su mejor amigo. Son estos los rasgos distintivos del «Curioso», cuyo protagonista tiene un papel bastante más complejo que el que desempeña habitualmente el celoso de la novelística italiana.

Pero volvamos a la labor interpretativa de Neuschäfer. En su comentario a los tres capítulos que contienen la novela del «Curioso», este crítico sostiene que Anselmo busca en su esposa una virtud ideal, algo imposible de encontrar, porque la perfección no es propia de la naturaleza humana (Neuschäfer 2005: II, 78). Cervantes, «lleno de un escepticismo bondadoso», abogaría por una virtud «posible», concediendo dignidad moral a la adúltera y condenando «la soberbia de un hombre, que por exigir lo imposible, es el único culpable de la degradación de su mujer» (Neuschäfer 2005: II, 79). Adviértase que lo que Neuschäfer considera como objeto de la búsqueda es la «virtud ideal». Prefiero formular de otro modo el programa de búsqueda del protagonista: Anselmo quiere saber si el parecer de Camila (su aparente bondad, su honradez) se corresponde con su ser más auténtico. El experimento de tentación ha de revelarle la «verdad», que, en teoría, puede resultar satisfactoria o decepcionante para él. Se comprende, desde este momento, que su irrefrenable deseo de saber es más fuerte que su miedo a perder a su esposa y que incluso un resultado negativo del experimento le dejaría con la satisfacción de haber descubierto la verdad. Así argumenta:

[...] deseo que Camila, mi esposa, pase por estas dificultades y se acrisole y quilate en el fuego de verse requerida y solicitada, y de quien tenga valor para poner en ella sus deseos; y si ella sale, como creo que saldrá, con la palma desta batalla, tendré yo por sin igual mi ventura [...]. Y cuando esto suceda al revés de lo que pienso, con el gusto de ver que acerté en mi opinión, llevaré sin pena la que de razón podrá causarme mi tan costosa experiencia (Cervantes 2005: I, 415).

La analogía entre el contenido de la novela interpolada y las peripecias de don Quijote consiste, según Neuschäfer, en que ambas historias se centran en 
un protagonista loco. «Las locuras de ambos tienen bastantes puntos de contacto», observa, porque «ambos someten la realidad a su idea, con la diferencia de que Anselmo parte de la $d u d a$ y don Quijote de la fe» (Neuschäfer 2005: II, 80) ${ }^{17}$. Hasta aquí, sería difícil no concordar con él. Curiosamente Neuschäfer, en el decurso de su argumentación, subraya siempre y solo la analogía entre ambos: «De la misma forma que don Quijote, Anselmo se inspira en un modelo ideal»; o bien: «igual que don Quijote, Anselmo está dominado de tal manera por su idea fija que no puede apreciar ya en su justa medida que el mundo que le rodea tiene su orden propio» (Neuschäfer 2005: II, 80). Pero, ¿son equiparables un marido incapaz de confiar en su esposa y don Quijote, que se entrega en cuerpo y alma a su empresa de restablecer la justicia en el mundo? Si existe un paralelismo entre sus «locuras», también se advierte una diferencia radical entre la actitud de quien se pone a mirar, desde cierta distancia, cómo tratan de seducir a su mujer sin intervenir cuando ella pide su ayuda, y el heroico gesto de quien se entrega, lleno de entusiasmo y de fe, a su misión redentora. No diría, por tanto, que «la consecuencia del experimento en ambos casos es la misma» (Neuschäfer 2005: II, 80). Es verdad que don Quijote fracasa, pero no sin haber encendido una centella de entusiasmo en el ánimo de Sancho, con quien ha sabido crear una amistad (jerárquica, es cierto, ya que la diferencia entre amo y criado jamás desaparece por completo). Don Quijote sabe crear relaciones humanas, mientras que Anselmo no sabe sino destruirlas. A mi modo de ver, más que de analogía, se trata de una relación antitética o, para utilizar otra terminología, de una analogía irónica, en cuanto se comparan dos formas de «locura», eso sí, y dos actitudes frente a la vida radicalmente opuestas.

Debido a su formación de «romanista», Neuschäfer se mueve con naturalidad en el terreno de la literatura comparada, donde se deja tentar, con cierta frecuencia, por el enfoque sociológico: le interesa reflexionar sobre la condición de la mujer en distintas épocas y sobre el «prefeminismo de Cervantes» (Neuschäfer 2006: 60). A través de una comparación de la virtud femenina en el Heptaméron de Marguerite de Navarre (antes de 1560), en el «Curioso» de Cervantes y en La princesse de Clèves, novela de Madame de La Fayette (1678), intenta ilustrar el «progresivo desencanto en el concepto de la moral en la novelística europea» (Neuschäfer 1999: 69-75). Marguerite de Navarre, en la novela XXVI de su obra, presenta un heroico combate entre el amor y el honor, en el que la virtud de una esposa triunfa a pesar de la imprudencia de su marido, quien ha favorecido sus contactos con un atractivo joven: la dama, aun estando enamorada de este galán, no sucumbe, pero el sobrehumano esfuerzo moral acaba por costarle la salud y la vida. Neuschäfer ve aquí una idea todavía tradicional de la virtud, propia de la civilización cortesana. Cervantes, en cambio, defendería «una ética de lo humanamente posible»: en

17. El subrayado es nuestro. 
su novela, se cuestionaría «nada menos que la autonomía del ser humano y su capacidad de auto-responsabilidad» (Neuschäfer 1999: 69).

Personalmente, no creo que Cervantes intentase realizar un estudio sobre la condición de las mujeres de hacia 1600. Su cuento se desarrolla en una mítica Florencia, metonimia no tanto de «Boccaccio», como se ha dicho, cuanto de «novela», de «obra de ficción»y, dentro de este teorema, Cervantes imagina una lucha despiadada entre dos hombres y una mujer. El comportamiento inicial de Camila, sin ser heroico, es humanamente comprensible: ella huye de Lotario, se indigna, escribe a su marido para que vuelva y, solo cuando se ve abandonada por él, cuando se da cuenta de que en absoluto le interesa su condición de mujer asediada, corresponde a los requiebros de su seductor. La conclusión que Cervantes extrae de esto, demuestra, en opinión de Neuschäfer, que «ni siquiera la voluntad moral más decidida puede resistir a la larga a la tentación y al asalto de las pasiones» (Neuschäfer 1999: 73). Ahora bien, que la virtud del ser humano no es invencible, se sabía perfectamente también en la época de Cervantes, puesto que los predicadores de la Contrarreforma no se cansaban de recordarlo. ¿Acaso no decía la Biblia que «hasta el justo cae siete veces al día» (Prov. 24, 16)? Pero hay algo más en esta novela, que Neuschäfer desatiende: existe una segunda Camila, la adúltera, que, a diferencia de Lotario, exhibe una fuerza y una inteligencia extraordinarias, valiéndose, en su lucha contra la fortuna adversa, de una «virtud» casi maquiavélica ${ }^{18}$. En el momento más crítico, la mujer recurre a un artificio y representa ante su marido (quien, como ella sabe, la está observando) «la tragedia de su honor». Camila logra su objetivo: de no intervenir la casualidad, Anselmo quedaría totalmente convencido de la lealtad de su esposa.

Para apreciar mayormente la importancia que corresponde al personaje femenino, nos conviene cambiar de perspectiva. Si examinamos la estructura de la novela y tenemos en cuenta la aportación semántica de cada una de las unidades discursivas, advertimos que el antagonismo entre Anselmo y Camila se invierte precisamente con el cambio de capítulo: mientras que en el capítulo XXXIII la manipulación (en el sentido de «mandar hacer») parte de Anselmo, quien obliga a Lotario a seguir sus instrucciones, en el capítulo XXXIV, es Camila. Las iniciativas importantes y, sobre todo, las que tienen carácter defensivo, proceden ahora de ella: ella es quien envía un criado a su marido, con una carta en que le amenaza con volver a casa de sus padres; quien sabe reaccionar ante los peligros (mientras que Lotario anda confuso y comete una imprudencia tras otra), quien recurre a la ficción para manifestar su inocencia y quien persuade a Anselmo (en el sentido de que le «hace creer» una versión de los hechos contraria a la verdad) mediante un dramático monólogo en que

18. Una enérgica defensa de Camila se encuentra en (Hutchinson 2010: 193-207). Observa Hutchinson que «el personaje que más enunciados pronuncia en el Curioso es Camila, lo cual señalaría su protagonismo en esta novela» (p. 200); y en el resumen final añade que «la crítica, con frecuencia, se ha conformado con culpar o minimizar a Camila sin apreciar su subjetividad ni sus excepcionales capacidades de amor y supervivencia» (p. 207). 
imita incluso a la casta y heroica Lucrecia romana, confundiendo así no solo a su marido, sino también a su amante.

Veamos ahora también la segunda lectura moral del «Curioso», realizada por Joachim Küpper (Küpper 2001: 387-421). Su estudio ofrece interpretaciones de tres de los cuentos intercalados en el Quijote: el de Marcela, el del Capitán y «El curioso impertinente». Küpper comienza con un elogio de este último, que le parece «de lo más fascinante que se ha producido en la tradición narrativa europea» (Küpper 2001: 387). La idea central de su estudio, a mi modo de ver, es la ambivalencia moral de las acciones humanas en la obra de Cervantes, las cuales, aun cuando comienzan siendo bien intencionadas, comportan aspectos reprobables. Así, la mora Zoraida desea vivir en tierras cristianas, pero, para realizar su sueño, tiene que abandonar a su anciano padre, quien, al advertir la intención de su hija, intenta quitarse la vida. Marcela, que desea vivir soltera en una comunidad en la que el matrimonio es la norma, es, según los aldeanos, culpable del suicidio de Crisóstomo: solo don Quijote la defiende. En ambos casos, nos las vemos con tentativas problemáticas de autorrealización, que traen a la memoria la autorrealización asimismo problemática de don Quijote. Convengo con Küpper en que entre el sueño pastoril de Marcela y la utopía caballeresca de don Quijote media una relación de analogía (Küpper 2001: 400, n. 39). Pero cuando el crítico trata de aplicar su modelo de lectura en el caso de Anselmo, no consigo seguirle. «Ninguno [de los tres personajes del «Curioso»] es realmente una mala persona», escribe Küpper, «ni en el sentido cristiano del pecado, ni en el antiguo de la hamartía» (Küpper 2001: 394) ${ }^{19}$. A mi entender, la curiositas de Anselmo no puede ser interpretada como un deslizarse poco a poco hacia una zona moralmente ambigua: para comprender que Anselmo comete, desde un principio, un grave error moral, no es necesario conocer la actitud de los teólogos, porque las consecuencias negativas de su petición son patentes. En su argumentación, Küpper considera tres momentos de la novela: 1) la preocupación de Anselmo recién casado por la vida del amigo, a quien pide que siga frecuentando su casa, no es, en sí, condenable. (Estoy conforme, pero esto ocurre antes de la revelación de su «impertinente deseo»). 2) Los «celos» de Anselmo no son necesariamente una expresión de maldad: pueden interpretarse «como miedo de quien teme ser abandonado o como lo contrario de la indiferencia», en la relación entre marido y mujer. Solo «el exceso de celos» es nocivo. (En realidad, Cervantes no habla aquí de «celos», pues no existe indicio alguno de infidelidad en la vida de la recién casada; habla de la obsesión de Anselmo por averiguar si la lealtad de su esposa es tan auténtica como parece). 3) La idea de Anselmo de llevar a cabo el experimento en secreto, en la intimidad de su casa, para evitar que la noticia cunda por la ciudad, denotaría por parte del marido «una seria preocupación por el honor de su esposa» (pero el honor es también suyo, por lo que Anselmo es bastante menos altruista de

19. El artículo de Küpper está redactado en alemán. La traducción de las citas es nuestra. 
lo que aquí se supone). Küpper sostiene que las acciones de los personajes cervantinos continúan siendo ambivalentes durante cierto tiempo, hasta que, en la parte última de la narración, se produce un repentino «exceso de pasión» que se revela irremediable. Pero este no es el caso de Anselmo. En la novela del «Curioso» veo yo una clara cesura, después de la tópica señal narrativa «sucedió que», con que suele empezar la acción novelesca propiamente dicha: es entonces cuando Anselmo confiesa a Lotario su intención de poner a prueba la virtud de Camila, con lo cual empieza a desencadenarse la tragedia. La interpretación de Küpper coincide con la de Neuschäfer donde observa que los personajes de los cuentos cervantinos carecen de phrónesis, esto es, de prudencia y capacidad de reflexionar ${ }^{20}$.

\section{MÁS ALLÁ DEL CONTENIDO MORAL: EL EJE TEXTO-LECTOR}

Es sintomático que Küpper no mencione nunca la particular disposición textual del «Curioso», interrumpida en el comienzo del capítulo XXXV por la irrupción nocturna de don Quijote y concluida solamente en la segunda parte de este capítulo. Cabani/Poggi, Ife y Neuschäfer, en cambio, destacan esta particularidad, y este último observa que Cervantes, recurriendo a esta técnica, hace alarde «de una consciente y muy pronunciada voluntad de construcción» (Neuschäfer 2005: II, 80). Neuschäfer señala asimismo el contraste estilístico entre la comicidad de la actuación de don Quijote (quien sale en camisa y bonete rojo a luchar contra los cueros de vino) y el final trágico de la novela, e interpreta el hecho de aparecer los dos protagonistas en el mismo capítulo como invitación a entrelazar ambas historias. Ahora bien, si la narración del «Curioso» no quedase interrumpida y si don Quijote saliese a librar su batalla solo después de concluida la novela (como Cervantes, probablemente, tenía proyectado, según indica el epígrafe del capítulo XXXVI, que se refiere aún a la batalla contra los pellejos de vino), tendríamos igualmente ese contraste entre lo trágico y lo cómico y esa contigüidad de Anselmo con don Quijote. La interpolación de un fragmento de la acción principal en la trama del «Curioso» debe de tener un motivo distinto: y es que el brusco cambio de escenario envuelve esta vez a los lectores, quienes tienen la sensación de volver de la literatura a la «vida», esto es, de la lectura de un cuento bastante abstracto al entorno familiar de la venta.

Fue el filósofo Julián Marías quien analizó por primera vez los procedimientos enunciativos de este capítulo, sin emplear, obviamente, este término (Marías 1957: 303-308). Le llamó la atención el hecho de que la interrupción de la novela leída, con personajes ficticios y «hasta inverosímiles», y la consecuente vuelta a la acción principal contribuyesen, en la imaginación del 
lector, a volver «más real» el mundo de don Quijote. En efecto, cuando el cura interrumpe su lectura y oímos al sonámbulo agitarse en la bodega, tenemos, por un momento, la impresión de haber vuelto a la «realidad», aunque solo hemos cambiado de nivel de ficción. El contraste entre la literatura y la vida es, con todo, aparente. El «Curioso» no es sino un manuscrito dentro de otro manuscrito, el del Quijote, con la diferencia de que la novela interpolada ha sido leída por uno de los personajes, mientras que la historia principal la va leyendo el lector. En el comienzo del capítulo XXXV, el lector experimenta un considerable effet de réel, pese a haber permanecido siempre dentro del mismo universo de ficción. El resultado de esta manipulación, consistente en el intento de «hacer creer verdadero», es comparable con el efecto que el monólogo teatral de Camila acaba de surtir en el ánimo de Anselmo.

La estructura discursiva del «Curioso» puede sintetizarse, por tanto, como sigue: en el capítulo XXXIII (= A1), Anselmo, el autor de la primera manipulación, consigue vencer las últimas resistencias de Lotario, pero este se enamora de Camila; en el capítulo XXXIV (= A2), Camila vence a su suerte adversa en cuanto persuade a Anselmo de su presunta inocencia. La cesura principal debe colocarse al final de A2. En la primera secuencia del capítulo XXXV (= B1), Cervantes juega con la credibilidad del lector, quien, mientras ríe del crédulo hidalgo que en su sueño heroico toma el vino por sangre, no se apercibe de ser víctima de otra manipulación que, esta vez, proviene del mismo texto; forma parte de $\mathrm{B}$ también el desenlace trágico de la novela $(=\mathrm{B} 2)$, en que los vencedores de A se convierten en vencidos y pagan su trasgresión con la muerte.

\section{¿IDENTIDAD ENTRE EL LENGUAJE Y EL SER? DE SU SUPUESTA IDENTIDAD A SU DESTRUCCIÓN}

En anteriores trabajos he intentado mostrar que la palabra «verdad», en sus distintas acepciones, es clave en la lectura de «El curioso impertinente» (Güntert 2007: 103-117) ${ }^{21}$. Entiendo «verdad», veritas, Wahrheit, en su sentido corriente, como correspondencia recíproca entre dos planos. Hemos visto, hasta ahora, que Anselmo se propone averiguar si existe una correspondencia entre el parecer y el ser de su esposa, y que su amigo Lotario intenta disuadirle con argumentos morales. Pero, una vez que la pareja ha consumado el adulterio, hay que persuadir a Anselmo de lo contrario mediante la ficción, como hace Camila. Con esto, ya se nos presentan tres acepciones del término

21. En su lectura del Quijote, Bruce Wardropper escribe al respecto: «The words verdad and mentira appear insistently in every chapter of Don Quixote», (Wardropper 1957: 598). Según este crítico conviene distinguir entre la «naturalidad» del relato principal y el «artificio literario» de algunas novelas intercaladas. Paralelamente, advierte un contraste entre la verdad «empírica» del mundo de Don Quijote y la verdad «artística» o «artificial» del «Curioso» (p. 597). 
«verdad»: como supuesta correspondencia entre parecer y ser frente al árbol de la vida; como verdad ejemplar dotada de un sentido alegórico-moral; y como resultado de un intento persuasivo. Las dos últimas acepciones, la ejemplaridad y la persuasión, tienen una evidente función literaria. En cuanto a la verosimilitud, es un elemento imprescindible en todo texto que se proponga ser creíble. Este concepto aristotélico es familiar al cura, quien comenta como sigue la historia del «Curioso»: «Bien me parece esta novela, [...] pero no me puedo persuadir que esto sea verdad», porque le parece que la historia «entre marido y mujer, algo tiene de imposible» (Cervantes 2005: I, 463). No todos tienen una concepción tan estrecha del concepto de verosimilitud como el cura del Quijote. El propio Aristóteles, en su Poética, conoce la categoría de lo «imposible verosímil» y admite, por consiguiente, las fábulas que rayan en lo imposible con tal de resultar creíbles ${ }^{22}$. Pues bien, la novela del «Curioso» pertenece a esta última categoría: comienza como un teorema, presentando un estado hipotético, ideal, inexistente en la realidad de cada día, para pasar, a continuación, a una serie de situaciones cada vez más intrincadas, que, no obstante, nos fascinan por ser humanamente plausibles. Más que en la concepción del teorema inicial, lo verosímil se halla en las partes propiamente dramáticas de la narración y, sobre todo, en las complicaciones de la trama originadas por Leonela. Su amante sale por la noche de la casa de sus dueños; lo cual, observado por Lotario, da lugar a un fatal equívoco. Movido por los celos, Lotario corre a denunciar a Camila ante el propio Anselmo, pero no tarda en confesar su imprudencia a su amante, causando una confusión general que parece irremediable.

Para terminar, un breve repaso de la novela puede ilustrar la transformación que padece el concepto de verdad. El primer párrafo del «Curioso» ofrece una prosa aún muy armónica, abundante en simetrías y dualidades, con sintagmas que fluyen sobre metros clásicos y tienden a compensar cualquier desigualdad -como lo hacen, en su vida diaria, «los dos amigos»-. Sus comportamientos, en un principio, se inscriben en el modo iterativo y en el movimiento cíclico, evidentes señales de una vida edénica. Observamos, de hecho, una llamativa correspondencia entre el plano del contenido (los dos amigos) y el plano de la expresión (sintaxis, ritmo, sonido), a la vez que se nos presenta un mundo ideal donde el lenguaje todavía se corresponde con el ser. La identidad de intenciones, propia de la amistad perfecta, se refleja en la identidad de los lexemas y sonidos. Releamos este comienzo:

En Florencia, ciudad rica y famosa de Italia, en la provincia que llaman Toscana, vivían Anselmo y Lotario, dos caballeros ricos y principales, y tan amigos, que, por excelencia y antonomasia, de todos los que los conocían «los dos amigos» eran llamados. Eran solteros, mozos de una misma edad y de unas mismas costumbres, todo lo cual era bastante causa a que los dos con recíproca amistad se correspondiesen. Bien es verdad que el Anselmo 
era algo más inclinado a los pasatiempos amorosos que el Lotario, al cual llevaba tras sí la caza; pero, cuando se ofrecía, dejaba Anselmo de acudir a sus gustos, por seguir los de Lotario, y Lotario dejaba los suyos, por acudir a los de Anselmo, y desta manera andaban tan a una sus voluntades, que no había concertado reloj que así lo anduviese (Cervantes 2005: I, 411)23.

En el primer párrafo, y solo en este, nos hallamos ante un mundo de puras esencias en el que palabras como lealtad y amistad dicen lo que son. Pero, a lo largo de la narración y, sobre todo, en sus compases últimos, se crearán situaciones muy distintas: debido a la disimulación y a la propagación de la mentira, el lenguaje deja de reflejar el ser para convertirse en un signo ambivalente. Lotario, incapaz de soportar la coacción de que es víctima, comienza a engañar a su amigo, a la vez que la honestidad de Camila se convierte en un mero parecer. La causa de la destrucción de la armonía inicial es la curiositas de Anselmo (lo que trae a la memoria la tesis de San Agustín según la cual el motivo del pecado de los primeros hombres fue la vana et curiosa cupiditas ${ }^{24}$.

Pero a Cervantes no le importa tanto contar de nuevo la historia del pecado original cuanto mostrar que el mundo en que vivimos es un mundo de apariencias; en estas condiciones se vuelve a plantear el problema de la verdad del lenguaje. Hemos visto que en el capítulo XXXIII, las citas literarias se distinguen por su carácter ejemplar: Lotario trae a colación el ejemplo del «prudente Reinaldos», precisando que este, aun siendo «ficción poética», «tiene en sí encerrados secretos morales dignos de ser advertidos»; recuerda el «consejo de un prudente viejo» acerca de la fragilidad del honor; recita una estancia de Las lágrimas de San Pedro, obra de Tansillo, sobre la vergüenza y el dolor del pecador arrepentido (El Greco representa a San Pedro llorando, porque el tema de la contrición del pecador era muy importante en la literatura religiosa de la Contrarreforma); y cita una copla de arte real, de autor desconocido, acerca de un hombre que buscaba «lo imposible» sin conseguir encontrar «lo posible». En el capítulo XXXIII, Lotario y el narrador ejemplar comparten aún los mismos valores ${ }^{25}$.

En el capítulo XXXIV, en cambio, los textos intercalados son sonetos de tema amoroso, obra de Lotario, que ya no pertenecen a la literatura ejemplar: uno de ellos habla de la ingratitud de una imaginaria "Clori», y otro, del tormento que experimenta el amante de una «bella ingrata»-lugares comunes del petrarquismo tardío. Es significativo que Camila, después de escuchar estos versos, pregunte a Lotario: «Luego ¿todo aquello que los poetas enamorados dicen es verdad?» A lo que Lotario contesta: «En cuanto poetas, no

23. El subrayado de las asonancias (los dos, dos los) es nuestro.

24. Aurelius Augustinus, Confessiones, X, 35. Acerca del concepto de la «curiosidad teórica» véase (Blumenberg 1961: 34-70).

25. Antonio Barnés Vázquez ha mostrado que tanto Lotario como el narrador lucen su erudición clásica. Si Lotario en su amonestación recuerda una anécdota de Plutarco y aduce un razonamiento aristotélico, el narrador, no sin ironía, compara a Camila ya con Penélope, ya con Porcia (Barnés Vázquez 2009: 227-230). 
la dicen [...], mas en cuanto enamorados, siempre quedan tan cortos como verdaderos» (Cervantes 2005: I, 450). Los poetas pueden estar apasionados, y algo de esto pasará a sus textos, pero la lírica amorosa no es verdadera en el sentido referencial. (Quien interpreta los sonetos así, de modo referencial, es Anselmo, porque imagina, lleno de orgullo, que la «bella ingrata» es su esposa.) Huelga insistir en que tampoco la representación teatral de Camila es verdadera en el sentido referencial: todo lo contrario. Camila miente al mismo tiempo que urde su artificio, pero dice verdad en lo referente a sus sentimientos de mujer humillada, herida. En su laberíntico discurso, se superponen la verdad y la mentira hasta el punto de crear otra «superior verdad». El propio Lotario comienza a dudar, no sabiendo ya a qué atenerse, y algo análogo le ocurre al narrador que, por primera vez, parece desorientado, pues se expresa, también él, de modo dubitativo: «porque [Camila], viendo que no podía haber a Lotario, o fingiendo que no podía, dijo...» (Cervantes 2005: I, 451) ${ }^{26}$. Las armas de Camila, en este momento, son la ficción y la fuerza persuasiva, a la vez que su modo de servirse de la verdad configura la persuasión literaria. Obsérvese, en el párrafo que describe el apogeo de su actuación, la frecuencia con que recurren los términos «verdad», «duda» y «mentira»:

Y, diciendo [Camila] estas razones, con una increíble fuerza y ligereza arremetió a Lotario con la daga desenvainada, con tales muestras de querer enclavársela en el pecho, que casi él estuvo en duda si aquellas demostraciones eran falsas o verdaderas, porque le fue forzoso valerse de su industria y de su fuerza para estorbar que Camila no le diese. La cual tan vivamente fingía aquel estraño embuste y falsedad, que por dalle color de verdad la quiso matizar con su misma sangre; porque, viendo que no podía haber a Lotario, o fingiendo que no podía, dijo:

-Pues la suerte no quiere satisfacer del todo mi tan justo deseo, a lo menos no será tan poderosa que en parte me quite que no le satisfaga.

Y haciendo fuerza para soltar la mano de la daga, que Lotario la tenía asida, la sacó y, guiando su punta por parte que pudiese herir no profundamente, se la entró y escondió por más arriba de la islilla del lado izquierdo, junto al hombro, y luego se dejó caer en el suelo, como desmayada.

Estaban Leonela y Lotario suspensos y atónitos de tal suceso, y todavía dudaban de la verdad de aquel hecho, viendo a Camila tendida en tierra y bañada en su sangre (Cervantes 2005: I, 450-451) ${ }^{27}$.

Creo que los ejemplos que he reunido, en estas consideraciones finales, muestran con suficiente claridad que la novela de «El curioso impertinente», además de tratar un complejo caso moral sobre la «verdadera virtud» de una mujer casada, propone una reflexión estética acerca de la «verdad» del lenguaje en el arte literario. Si se comparan el principio y el final de la narración, se advierte una profunda transformación del concepto «verdad»: desde un primer 
estado ideal, en que el lenguaje todavía se corresponde con el ser, a través de una sucesión rápidamente cambiante de situaciones cada vez más ambiguas, en las que el lenguaje deja de revelar lo que ocurre realmente. Ante esta conversión de las palabras y los gestos en meros signos, propios del mundo de las apariencias, es lícito preguntar si el error de Anselmo no consiste precisamente en su pretensión de remontarse desde el plano del parecer hasta el origen del ser, que es inasequible al conocimiento humano. Lotario, por su parte, comienza fingiendo, pero, después de un cierto tiempo, se identifica con su papel de seductor y se apasiona de veras, requebrando a Camila «con tanta turbación y con tan amorosas razones que [ella] quedó suspensa» (Cervantes 2005: I, 432). Ahora bien, paralelamente a la degradación moral de los personajes, observamos un progreso cognoscitivo en la reflexión, inherente al texto, acerca de la verdad del lenguaje en el espacio literario, en el que el cuento se inscribe. Quien configura esta transformación de la «verdad» en sede literaria es Camila. No es ninguna casualidad que su primera manifestación verbal sea de tipo escrito, la carta que ella envía a su marido, y que su segunda intervención, pronunciada en discurso directo, plantee la cuestión de la verdad de la poesía. La tercera vez que toma la palabra es cuando conversa con Leonela, a la que confía su miedo a perder la estima de Lotario, lo cual ocurre efectivamente poco después y hace inevitable una reacción defensiva de Camila: su monólogo dramático es una obra maestra de la persuasión artística. En esta escena culminante, Camila se convierte en figura de la «verdad de la literatura». La insistente presencia del tema literario en la narración de «El curioso impertinente» condice con su carácter «escrito», necesitado de una lectura. Podemos concluir, por tanto, que de entre los cuentos intercalados en el primer Quijote el único «cuento leído», con características llamativamente literarias, constituye a la vez el núcleo teórico de la obra: se nos presenta como un lugar privilegiado de la reflexión ética y estética, que permite a Cervantes meditar sobre el lenguaje y sus posibilidades de ser verídico en un mundo de apariencias disociadas del ser.

\section{BIBLIOGRAFÍA CITADA}

Alarcos García, Emilio (1950). «Cervantes y Boccaccio», en VVAA. Homenaje a Cervantes. Estudios cervantinos, II. Francisco Sánchez-Castañer (ed.). Valencia: Mediterráneo, pp. 345-383.

Alvar, Carlos (2001). «Boccaccio en Castilla: entre recepción y traducción», en María Hernández Esteban (ed.), La recepción de Boccaccio en España, núm. extraordinario de Cuadernos de Filología Italiana, 7-9. Madrid: Universidad Complutense, pp. 333-350. Aristóteles (2006). Poetica. Poetik. Manfred Fuhrmann (ed. y trad.) Stuttgart: Reclam.

Ariosto, Ludovico (1966). Orlando furioso. Lanfranco Caretti (ed.) Torino: Einaudi.

Arriola, Paul M. (1971). "Varia fortuna de la historia del rey Candaules y El curioso impertinente», Anales Cervantinos. 10, pp. 33-50.

Augustinus, Aurelius (2012). Confessiones. Bekenntnisse. Kurt Flasch y Burkhard Mojsisch (ed.) Stuttgart: Reclam. 
Avalle-Arce, Juan-Bautista (1975). «El cuento de los dos amigos», Nuevos deslindes cervantinos. Barcelona: Ariel, pp. 153-214.

Ayala, Francisco (1971). «Los dos amigos», en Los ensayos. Teoría y crítica literaria. Madrid: Aguilar, pp. 695-713.

Barbagallo, Antonio (1994). «Los dos amigos, El curioso impertinente y la literatura italiana», Anales Cervantinos. XXXII, pp. 207-219.

Babinger, Georg (2013). Wanderungen und Wandelungen der Novelle von Cervantes «El curioso impertinente». London: Forgotten Books (reimpresión de su tesis doctoral de Erlangen: Junge, 1911).

Bandello, Matteo (1966). Tutte le opere di Matteo Bandello, a c. de Francesco Flora, vols. I y II, Milano: Mondadori.

Bárnez Vázquez, Antonio (2009). «Yo he leído en Virgilio». La tradición clásica en el «Quijote». Vigo: Academia del Hispanismo.

Blumenberg, Hans (1961). «Augustins Anteil an der Geschichte der theoretischen Neugierde», Revue d'Études Augustiniennes et Patristiques. 7, pp. 34-70.

Bravo Ramón, Francisco Javier (2013). «El curioso impertinente»: periplo mediterráneo de un mito clásico, Vigo: Academia del Hispanismo.

Boccaccio, Giovanni (1976). Tutte le opere di Giovanni Boccaccio. Vittore Branca (a c. di), vol. IV, Decameron. Milano: Mondadori.

Boccaccio, Giovanni (1983). Tutte le opere di Giovanni Boccaccio. Vittore Branca (a c. di), vol. IX, De casibus virorum illustrium. Pier Giorgio Ricci e Gregorio Zaccaria (a c. di) Milano: Mondadori.

Cabani, Maria Cristina y Poggi, Giulia (2006). «Peccati di curiosità (Furioso XLII-XLIII Quijote I, 33-35)», Studi Mediolatini e Volgari. 52, pp. 5-31.

Carrascón, Guillermo (2014). «Oneste o ejemplares: Bandello y Cervantes», Artifara. 13bis, pp. 285-305.

Cervantes, Miguel de (1987). La Galatea. J. Bautista Avalle-Arce (ed.), Madrid: Espasa Calpe.

Cervantes, Miguel de (2005). Don Quijote de la Mancha. Francisco Rico (ed. del Instituto Cervantes dirigida por). Barcelona: Galaxia Gutenberg. 2 vols.

Cervantes, Miguel de (2003). Los trabajos de Persiles y Sigismunda. Carlos Romero Muñoz (ed.) Madrid: Cátedra.

Covarrubias Horozco, Sebastián de (2006). Tesoro de la lengua castellana o española. Ignacio Arellano y Rafael Zafra (ed. integral e ilustrada). Pamplona: Universidad de Navarra.

Dictionnaire de la spiritualité (1953). Dir. por Marcel Viller S. J.. Paris: Beauchesne.

Di Pinto Elena (1999). «De cuernos y celos: un problema de intertextualidad entre Straparola, Bandello y Cervantes», en González Vicente (ed.), Amor y erotismo en la literatura. Salamanca: Caja Duero, pp. 267-276.

González, Eduardo (1993). «Curious Reflex, Curious Reflections: The Case of Impertinence», en Ruth El Saffar y Diana Wilson de Armas (coord.), Quixotic Desire: Psychoanalytic Perspectives in Cervantes. Ithaca: Cornell University, pp. 200-226.

Güntert, Georges (2007). «El Quijote, El curioso impertinente y la verdad de la literatura», en Cervantes. Narrador de un mundo desintegrado. Vigo: Academia del Hispanismo, pp. 103-117.

Guillén de Castro (1991). El curioso impertinente. Christiane Faliu-Lacourt y María Luisa Lobato (ed. crítica de). Kassel: Reichenberger.

Illades Aguiar, Gustavo (1995). «El honor como espectáculo en la Novela del curioso impertinente», en Giuseppe Grilli (coord.), Actas del II Congreso Internacional de la Asociación de Cervantistas. Napoli: Istituto Orientale, pp. 487-495.

Henkel, Arthur y Schöne, Albrecht (1996). Emblemata. Handbuch zur Sinnbildkunst des XVI. und XVII. Jahrhunderts. Stuttgart: Metzler. 
Herodotus (1987). Historiae. Ed. de Haiim B. Rosén, 2 vols.. Leipzig: Teubner.

Huarte de San Juan, Juan (1989). Examen de ingenios para las ciencias. Guillermo Serés (ed.). Madrid: Cátedra.

Hutchinson, Steven (2006). «Anselmo y sus adicciones», en Gustavo Illanes y James Iffland (coords.), El Quijote desde América. Puebla y México: Universidad Autónoma y El Colegio de México, pp. 119-138.

Hutchinson, Steven (2010). «Norma social y ética privada: el adulterio femenino en Cervantes», Anales Cervantinos. 42, pp. 193-207.

Ife, Barry W. (2005). «Cervantes, Herodotus and The Eternal Triangle: Another Look at the Sources of El curioso impertinente», Bulletin of Hispanic Studies. 82, pp. 671-681.

Ife, Barry W. y Thacker, J. (ed.) (2013), The Complete Exemplary Novels. Oxford: Aris and Phillips Hispanic Classics.

Krueger, Alison E. (2009). «Cervantes's Laboratory: The Thought Experiment of $\mathrm{El} \mathrm{Cu}$ rioso Impertinente», Cervantes: Bulletin of the Cervantes Society of America. 29, 1, pp. 117-165.

Küpper, Joachim (2001). «Die Novelas intercaladas in Cervantes' Quijote», Romanistisches Jahrbuch. 52, pp. 387- 421.

Lucas de Dios, José María (1999). «El curioso impertinente de Cervantes. Peripecias de un mito griego», en Mauricio Pérez González et al. (coords.), Pervivencia de la tradición clásica: homenaje al profesor Millán Bravo, Valladolid: Universidad de Valladolid, pp. 159-182.

Marías, Julián (1957). «La pertinencia del Curioso impertinente», en Obras, 10 vols. Madrid: Revista de Occidente, III, pp. 303-308.

Mc Grady, Donald (1994). «Otra vez las fuentes de El curioso impertinente», en Francis Cerdan (coord.), Hommage à Robert Jammes, 3 vols. Toulouse: Presses Universitaires du Mirail, II, pp. 767-772.

Morón Arroyo, Ciriaco (2000). «El curioso impertinente y el sentido del Quijote», en Francisco La Rubia Prado (coords.), Cervantes for the 21st Century / Cervantes para el siglo XXI: Studies in Honor of Edward Dudley. Newark: Juan de la Cuesta, pp. 163-183.

Neuschäfer, Hans-Jörg (1989). «El curioso impertinente y el sentido del Quijote», Anthropos. 98-99, pp. 104-107.

Neuschäfer, Hans-Jörg (1990). «El curioso impertinente y la tradición de la novelística europea», Nueva Revista de Filología Hispánica. 38, pp. 605-620.

Neuschäfer, Hans-Jörg (1999). La ética del Quijote. Función de las novelas intercaladas. Madrid: Gredos.

Neuschäfer, Hans-Jörg (2005). «Lecturas del Quijote», cap. 33-35, en Don Quijote de la Mancha, 2 vols., F. Rico (dir.). Barcelona: Gutenberg, II, pp. 77-81.

Neuschäfer, Hans-Jörg (2005). «Boccaccio, Cervantes und der Diskurs der Utopie», en Christoph Strosetzki (ed.), Miguel de Cervantes' «Don Quijote». Explizite und implizite Diskurse im «Don Quijote». Berlin: Erich Schmidt, pp. 149-160.

Neuschäfer, Hans-Jörg (2014). «Von der novella zur novela. Cervantes und die frühneuzeitliche Boccaccio-Rezeption in Spanien», en Aurnhammer, Achim y Stillers, Rainer (coords.), Giovanni Boccaccio in Europa. Studien zu seiner Rezeption in Spätmittelalter und Früher Neuzeit. Wiesbaden: Harassowitz, pp. 103-112.

Neuschäfer, Hans-Jörg (2006). «Utopía y prefeminismo en el Quijote de 1605», en Eleonora Basso y Alicia Torres (coords.), Actas de las Jornadas Cervantinas a cuatrocientos años de la publicación del «Quijote». Montevideo, 28, 29 y 30 de setiembre de 2005. Montevideo: Universidad de la República, pp. 60-69.

«Ovide moralisé». Poème du commencement du XIVe siècle (1931). Ed. de Cornelius De Boer (et al.), vols. I-III. Amsterdam: Koninklijke Nederlandse Akademie.

Ovidius, Publius Naso (1968). Metamorphosen. Ed. de Erich Rösch. München: Heimeran. 
Pichler, Regina (1986). Die Gygesgeschichte in der griechischen Literatur und ihre neuzeitliche Rezeption. München: Uni Druck.

Platón (2000). Der Staat / Politeia. Ed. de Thomas A. Szlezák, trad. de R. Rufener. Düsseldorf-Zürich: Artemis und Winkler.

Pulgar, Hernando del (1929). Glosas a las «Coplas de Mingo Revulgo». Madrid: Clásicos Castellanos.

Stein Louise K. (ed.) (2014). Juan Hidalgo: Celos aun del aire matan. «Fiesta cantada» (opera in three acts) with text by Calderón de la Barca. Middleton Wis.: A-R-Editions, «Introduction», pp. ix-xvii.

Thomas de Aquino, Summa theologica (2006). Ed. de Brian Davies (et al.). Cambridge: Cambridge University Press.

Vega Carpio, Lope de (1973). El peregrino en su patria. Ed., introducción y notas de Juan Bautista Avalle-Arce. Madrid: Castalia.

Wardropper, Bruce (1957). «The pertinence of El curioso impertinente», Publications of Modern Language Association. 72, pp. 587-600.

Wilson, Diana de Armas (1987). «"Passing the Love of Women": The Intertextuality of El curioso impertinente», Cervantes. 7, pp. 9-28.

Zimic, Stanislav (1994). «Introducción a las Novelas ejemplares». Anales Cervantinos. 32, pp. 23-95.

Zimic, Stanislav (1998). Los cuentos y las novelas del «Quijote». Madrid: Vervuert.

Recibido: 3 de diciembre de 2014

Aceptado: 22 de junio de 2014

\section{Resumen}

En esta revisión de «El curioso impertinente», que incluye un panorama de la historia de su recepción en los últimos veinte años, se comparan los resultados de cuatro lecturas con la de quien escribe. La relección crítica de estas interpretaciones, que adoptan perspectivas distintas, se desarrolla en tres etapas: en primer lugar, se examinan algunas propuestas relacionadas con las fuentes de la novela, sin abandonar la idea de que la novela del «Curioso» es obra profundamente original; después, se comentan las cuatro lecturas, que tienen en común la tendencia a privilegiar el análisis del contenido; por último, se insiste en la necesidad de superar una exégesis limitada a las cuestiones argumentales y de prestar atención también a los aspectos narrativos y discursivos.

Palabras clave: Quijote; Historia de la recepción; Fuentes; Discurso; Reflexión intrínseca; Verdad literaria.

\section{Title: New Critical Perspectives on «El curioso impertinente»}

\section{Summary:}

In the present revision of «El curioso impertinente», which includes a survey of the History of its Reception in the course of the last twenty years, the results of four critical readings are compared with that of the author of this article. The critical re-reading of these interpretations, all of which adopt different perspectives, is developed in three stages: first some suggestions concerning the sources of the novella are examined, without giving up the conviction that the tale of «El curioso» is a profoundly original text; subsequently, the four interpretations, which share the tendency of give priority to the analysis of content, 
are commented on; finally the point is made that it is necessary to overcome an interpretation limited to questions of plot development, in order to look more closely at narrative and discursive aspects.

Keywords: Don Quixote; History of the Reception; Sources; Discourse; Intrinsic Reflections; Literary Truth. 